\title{
Regulation of the human stress response gene GADD153 expression: role of ETS1 and FLI-1 gene products
}

\author{
Arun Seth ${ }^{1}$, Sergio Giunta ${ }^{2}$, Claudio Franceschil ${ }^{3}$, \\ Ismail Kola ${ }^{4}$ and Marco C Venanzoni ${ }^{, 2,5}$ \\ ${ }^{1}$ Medical Research Council Group in Periodontal Physiology and Department of \\ Laboratory Medicine and Pathobiology, University of Toronto, and Laboratory \\ of Molecular Pathology, Women's College Hospital, Toronto, Ontario M5S \\ 1B2, Canada \\ 2 Laboratory of Molecular Oncology, Department of Laboratory Medicine, \\ INRCA Geriatric Hospital 'U.Sestilli', Ancona 60100, Italy \\ ${ }^{3}$ Department of Gerontological Research, INRCA, Ancona 60100, and \\ Department of Experimental Pathology, via S. Giacomo 12, Bologna 40126, \\ Italy \\ ${ }^{4}$ Monash Medical Center, Melbourne, Australia \\ ${ }^{5}$ Istituto Tecnologie Biomediche, ITBM- CNR, Roma, Italy \\ * corresponding author: Marco C Venanzoni, Laboratory of Molecular \\ Oncology, INRCA Geriatric Hospital “U.Sestilli”, Ancona 60100, Italy. \\ e-mail:mc.venanzoni@inrca.it
}

Received 23.2.99; revised 13.7.99; accepted 19.7.99

Edited by R Knight

\begin{abstract}
We have previously shown that ETS transcription factors, regulate cell growth and differentiation, and ETS1 and ETS2 are able to transcriptionally regulate wt $\mathrm{p} 53$ gene expression. In the present study we show that the ETS transcription factors also play a role in regulating expression of GADD153, a wtp53 inducible gene, which induces growth arrest and apoptosis in response to stress signals or DNA damage. We report the presence of a single EBS in the human GADD153 promoter, and that the GADD45 gene promoter lacks EBSs. The GADD153 promoter EBS shows a very high affinity for ETS1 and FLI-1 gene products. In addition, our data show that both ETS1 and FLI-1 strongly activate transcription of the GADD153 EBS linked to the CAT reporter gene. Our results also demonstrate how ETS1 and FLI-1 specifically regulate GADD153 expression. In addition, ectopic ETS2 protein expression resulted in only a weak induction of the same CAT reporter construct. The ETS1 and FLI-1 proteins provide a novel mechanism of activation for GADD153, allowing these two ETS genes to control its expression during cell growth and differentiation, rather than in response to oxidative stress.
\end{abstract}

Keywords: apoptosis; ETS1; GADD153; FLI-1; p53; gene expression

Abbreviation: EBS, ETS binding site

\section{Introduction}

Numerous studies have highlighted the paramount role of the p53 gene product in regulating apoptosis, ranging from G1 cell cycle checkpoint control to DNA repair, signal transduction and transcriptional activity on effector genes. ${ }^{1-3}$ It is likely that wt p53 regulation of downstream effector genes, such as GADD45, GADD153 and WAF1/ Cip1, activates the G1-S checkpoint. ${ }^{4-7}$ These p53responsive genes induced by DNA damage and growth arrest, are transactivated by wt-p53 through a specific consensus DNA sequence consisting of two copies of a symmetric $10 \mathrm{bp}$ motif separated by $0-13 \mathrm{bp}$ in their promoter or enhancer regions. ${ }^{3,8}$ GADD153 differs from GADD45 and other growth arrest and DNA damage (GADD) inducible genes because its basal expression is absent or undetectable under normal growth conditions, yet is strongly induced in response to cellular stress by a wide variety of agents that cause either DNA-damage or cell cycle arrest. ${ }^{9}$ These include UV light, hypoxia, serum starvation, medium depletion, toxins, metabolic inhibitors, various chemoterapeutic drugs. ${ }^{9-17}$ These elements are thought to stimulate GADD153 expression through different pathways.

The complex regulation of GADD153 is neither cell cycle dependent, nor exclusively under wtp53 control. ${ }^{11,12,18-20}$ For example, an AP-1 responsive element in the GADD153 promoter has been shown to be highly specific for oxidative stress, yet it does not activate GADD153 expression after DNA damage nor does it respond to the phorbol ester TPA, which increases AP-1 activity. ${ }^{18,21,22}$

Previously, we have demonstrated that human p53 is transcriptionally regulated by ETS1 and ETS2 proteins by binding to a dual EBS palindromic structure on its promoter, and that their expression is closely linked during mouse embryogenesis. ${ }^{23}$ ETS genes control cell growth and differentiation in a tissue-specific manner, presumably regulating genes involved in the regulation of apoptotic pathways. ${ }^{23-25}$ ETS1, in particular, is thought to play a crucial role in apoptosis in normal and neoplastic cells. ${ }^{24,25}$ FLI-1 has also been reported to inhibit apoptosis in a number of human tumors. ${ }^{26}$ Both ETS1 and ETS2 have been reported to transactivate junB transcription, a member of the AP-1 family of transcription factors capable of participating in the formation of the AP-1 complex. ${ }^{27}$ In response to genotoxic stress, another ETS family transcription factor, E1AF, has been found to upregulate transcription from the Waf1/Cip1 promoter, where two EBS partially overlapping with two p53 binding sites are present. ${ }^{28}$ All the ETS proteins bind to a GGAA/T purine-rich core sequence, and share a highly homologous DNA-binding domain of 85 amino acids. ${ }^{29}$ This suggested to us that other ETS proteins binding similar sequences might have roles in 
the regulation of p53 effector genes. In the present study, we investigated the role of ETS1, ETS2, and FLI-1 transcription factors in the regulation of the human GADD153 gene to further characterize a novel p53dependent ETS pathway.

\section{Results}

\section{Identification of an ETS binding sequence in the GADD153 promoter}

Previous studies have demonstrated the role of ETS proteins in the regulation of $\mathrm{p} 53$ expression, ${ }^{23}$ and the overlapping patterns of expression of ETS1, ETS2 and p53 during mouse embryogenesis. $^{23,30-32}$ To further analyze the role of the ETS family transcription factors on the pathway of programmed cell death, we searched for the presence for ETS binding site (EBS) in the human GADD45 and GADD153 promoters by computer sequence analysis. We identified a single EBS in the GADD153 promoter at position -201 to -195 (Figure 1), no EBS was found in the GADD45 promoter (data not shown).

\section{ETS1 and FLI-1 proteins bind with high affinity to the EBS in the human GADD153 promoter}

To investigate whether ETS proteins could specifically bind to the EBS sequences in the GADD153 promoter two pairs of oligonucleotides corresponding to the wild-type (WT) GADD153 EBS-promoter sequence and to a mutant (MUT) EBS-promoter sequence were synthesized (Figure 2) and used in gel shift assays with in vitro expressed ETS1 and FLI1 proteins (Figure 3). The mutant GADD153 EBS-promoter oligonucleotide contains a single point-mutation replacing the second cytosine of the EBS, position - 196, with a thymidine. Earlier work with methylation interference analysis indicated that this mutation negatively affects the DNA sequence binding specificity of ETS proteins. ${ }^{33,34}$

FLI-1 protein bound strongly to the wt GADD153 EBS oligonucleotide probe in a sequence specific manner

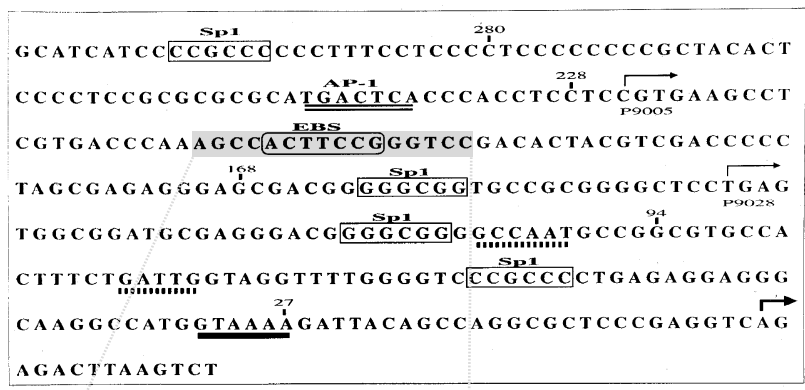

\section{AGCCACTTCCGGGTCC}

Figure 1 Structure of the human GADD153 promoter. Sp1 binding sites are boxed. AP-1 binding site is indicated by double solid underlines. Dashed lines indicate putative CAAT elements. The two arrows show the position of two of the three plasmid constructs used in the CAT assays experiments. A bold solid line indicate the GADD153 TATA box, and the bold arrow the transcription initiation start site. The ETS Binding Site (EBS) is highlighted. The sequence of the EBS is shown below
(Figure 3A), as the FLI-1 protein:GADD153 DNA complex was completely inhibited in presence of excess cold oligonucleotide (Figure 3A, lane 4). FLI-1 protein affinity for the GADD153-EBS DNA sequence was estimated by complexing the protein with equal amounts of oligonucleotide probes containing either an optimal FLI-1 binding site

\begin{tabular}{|l} 
GADD153 WT Oligonucletides \\
ES 5'- CAA ACG CAC TTC CGG GTC CAA GAC - 3' Sense \\
EA 5'- GTC TTG GAC CCG GAA GTG GCT TTG - 3' Anti-Sense
\end{tabular}

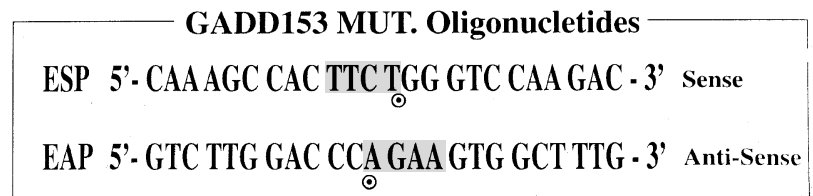

Figure 2 GADD153 promoter sequences. Two pairs of short oligonucleotides, containing the wild-type (WT) and a point-mutated (MUT) nucleotide sequences of the human GADD153 promoter, were synthesized for use in gel shift assays. ETS binding regions are highlighted, dots indicate the single base mutation used

ETS1-3 GADD153 E74 Oligo

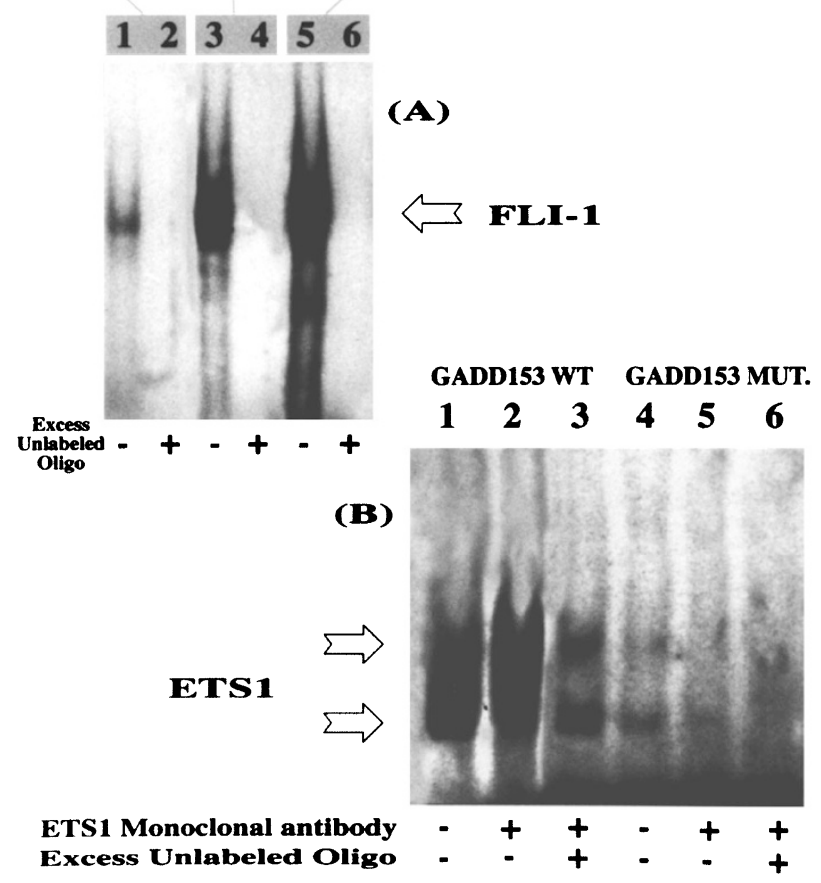

Figure $3 \mathrm{FLI}-1$ and ETS1 proteins bind to the GADD153 promoter. End labeled DNA fragments, corresponding to the different GADD153-EBS wildtype or modified sequences, and to the ETS1-3 and E74 sequences, were incubated with an extract of ETS1 and FLI-1 nuclear extracts produced by the baculoviral system in SF-9 insect cells, and analyzed on a $4 \%$ non-denaturing polyacrylamide gel. The binding was carried out in the presence of excess oligonucleotides (lanes $2-4$ and 6 of $\mathbf{A}$; lanes 2 and $4 \mathbf{B}$ ), in the presence of ETS1 monoclonal antibody E44, (lanes 3 and 6 in B). Arrows indicate the ETS1 protein:DNA complex and its supershift by the ETS1 specific antibody 
(E74) or an optimal ETS1 binding site (ETS1-3). We observed that the signal intensity of the $\mathrm{FLI}-1$ protein DNA complex with the GADD153 WT EBS probe (Figure $3 A$, lanes $3-4$ ) was comparable to the complex with E74 probe (Figure $3 A$, lanes $5-6$ ) and higher than for the ETS1-3 probe (Figure $3 A$, lanes $1-2$ ).

ETS1 protein binds to the wild-type GADD153 EBS promoter sequences with very high affinity (Figure 3B). This binding is sequence specific because the ETS1 protein:DNA complex was supershifted and stabilized in the presence of the monoclonal antibody E44 specific for ETS1 protein (Figure 3B, lane 2, upper arrow), and the binding was inhibited in the presence of excess cold oligonucleotide (Figure 3B, lane 3, lower arrow). The ETS1 protein did not show any detectable binding activity when the labeled mutant GADD153 oligo was used as a probe (Figure 3B, lanes 3-6).

\section{ETS1 and FLI-1 expression transactivate transcription of the CAT reporter gene}

The binding modalities of the ETS1 and FLI-1 proteins suggested that both these proteins may function in transcriptional control of GADD153 through the EBS present on its promoter. To assess the role of ETS1, FLI-1 and ETS2 in activating transcription from the human GADD153 promoter, three CAT reporter plasmids containing serial deletions in the GADD153 promoter region were constructed and cotransfected in COS cells with expression plasmids for ETS1 (pSGE1), ETS2 (pSGE2), and FLI1 (pSGT20) (Figures 4 and 5). p9000 contains the entire wild type GADD153 promoter region (position -778 to +21 ). p9005 retains the EBS and the minimal promoter region (position -250 to +21 ). In p9028 the EBS is deleted, leaving only the minimal promoter region (position -141 to +21 ).

Both ETS1 and FLI-1 products stimulated transcription with similar efficiency from the full length GADD153

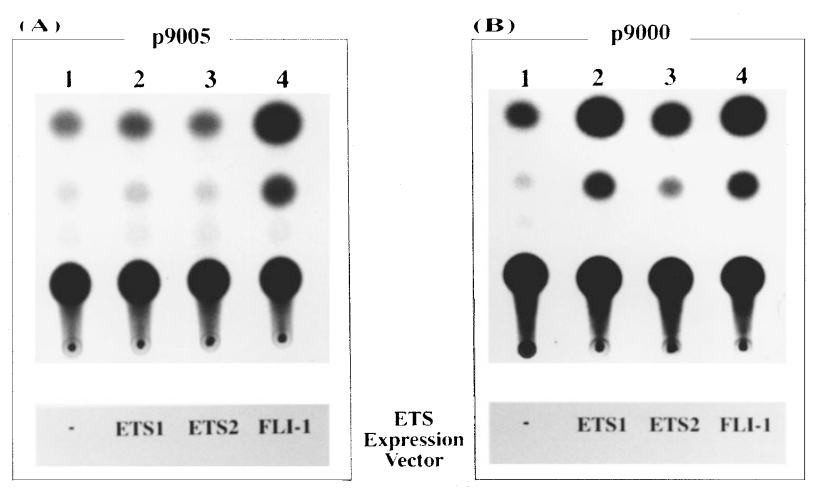

Figure 4 ETS proteins transactivate the GADD153 promoter via the EBS region. (A) represent p9005 CAT reporter plasmid activity, with the minima conserved EBS GADD153 promoter region. (B) p9000 CAT reporter plasmid activity, with the entire conserved GADD153 promoter region. The expression plasmids pSGE1(ETS1), pSGE2 (ETS2) were obtained by cloning DNA fragments of ETS1 lacking exon 7, ETS1, ETS2 genes, respectively, at the BamHI site of vector pSG5 (Stratagene, California, USA). Transfections were done in duplicate, repeated at least three times, and the CAT activity was examined by thin-layer chromatography promoter-reporter construct (Figure 4A,B). Very weak transactivation was observed when p9000 was cotransfected with the ETS2 expression vector (Figure 4B), and no CAT activity was detected in the controls (Figure 4B). When the upstream region -778 to -225 was deleted (p9005) the transcriptional activity by ETS1 protein was strongly reduced, and that of ETS2 protein was completely abolished (Figure 4A). In contrast, FLI-1 protein showed a strong increase in reporter activity with the p9005 plasmid (Figure 4A). Figure 5 summarizes the results of reporter gene assays for each GADD153EBS-CAT plasmid, including induction ratios.

\section{Discussion}

GADD45 and GADD153 are two potent mediators of p53 in response to a variety of DNA damaging agents, inducing directly or indirectly G1 arrest and/or apoptosis. ${ }^{35}$ GADD153 has been consistently linked to the differentiative processes of myeloid cells and adipocytes ${ }^{20,36,37}$ and represents a crossroads for multiple signal transduction pathways, being a transcriptional inhibitor of many C/EBP target genes involved in differentiation, ${ }^{17}$ and for its direct role in mediating $\mathrm{G} 1$ arrest and apoptosis. ${ }^{9,18,20,21,35}$

Although GADD45 is strictly under the control of p53, its gene regulation seems to be not solely under wtp53 control. ${ }^{12,19}$ There is evidence to indicate the existence of multiple pathways for induction of GADD153 expression in response to different metabolic or genotoxic stimuli which cause cell cycle arrest. ${ }^{18,21}$ In addition, GADD153 expression seems to be mainly under transcriptional regulation rather than through the stabilization of its mRNA. $^{38}$ A single AP-1 responsive element present in the GADD153 promoter is critical for GADD153 induction in response to oxidative stress, ${ }^{22}$ but unable to evoke any transactivation of GADD153 after DNA damage. ${ }^{18,21}$ TPA stimulation, which increases AP-1 activity, fails to induce binding of the AP-1 complex to the AP-1 binding site, as well as GADD153 expression. ${ }^{18,21}$

Recently, a member of the ETS family of transcription factors, ETS1, was shown to be up-regulated by oxidative stress, thus inducing angiogenesis with proliferation and migration of endothelial cells. ${ }^{39}$ ETS genes are a highly phylogenetically conserved family of transcription factors, with important control functions over cell growth and differentiative processes during embryogenesis and throughout adulthood. ${ }^{29,30,33,40-44}$ Among the large ETS gene family, ETS1, ETS2 and FLI-1 seem to be consistently involved in the induction and/or repression of apoptosis, with consequent effects on cell proliferation and differentiation. ${ }^{24,25,45-48}$

Previously, we have shown that p53 is regulated by ETS1 and ETS2 proteins, and the expression patterns of these genes correlate during mouse embryonic development. ${ }^{23}$ p53 transcriptional regulation takes place through a palindromic ETS binding structure in the human wtp53 promoter, where two EBS repeats of $10 \mathrm{bp}$ are present in a 'head-to-head' conformation, separated by four bases. ${ }^{23}$ Interestingly, the Waf1/Cip1 gene promoter presents two EBS partially overlapping with two p53 binding sites, and it 


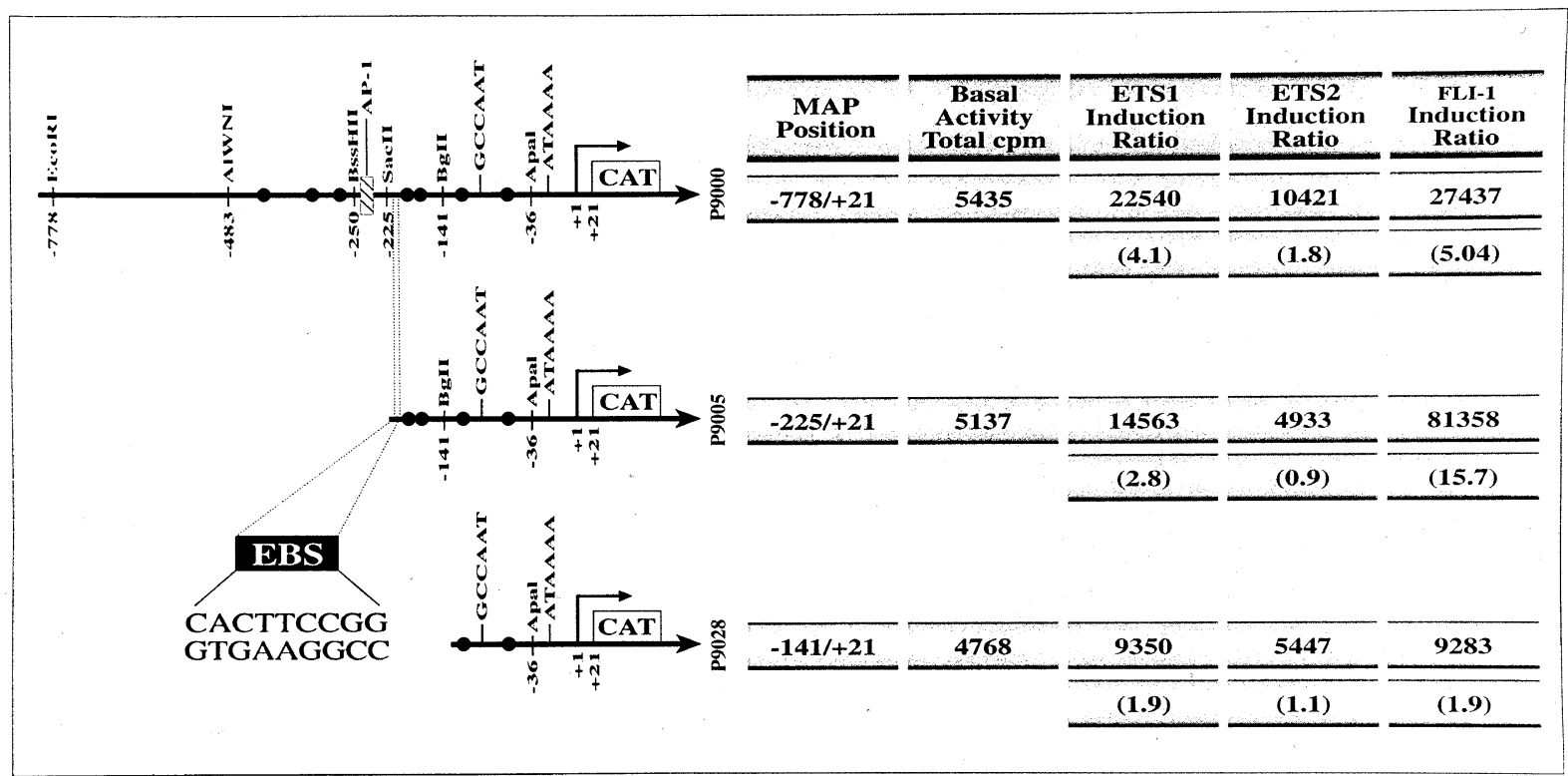

Figure 5 GADD153 EBS pBLCAT plasmids activity. GADD153 CAT reporter plasmids p9028, p9005, p9000 (left from bottom to top). CAT activity in cpm and induction ratios for each construct with three different ETS proteins (right)

is positively regulated by the transcription factor $\mathrm{E} 1 \mathrm{AF}$, another ETS related gene product, induced in response to genotoxic stress. ${ }^{28}$ Besides, their possible direct role in the regulation of GADD153 and p53 expression, ${ }^{23}$ ETS factors may also affect indirectly GADD153 transcriptional activation, by promoting junB expression, a constitutive component of the AP-1 transcriptional activation complex. ${ }^{27}$ Based on these data, ETS family proteins are good candidates to represent the unknown transcription factors proposed by Luethy and Holbrook to be involved in transcriptional regulation of p53 target genes. ${ }^{18}$

We have investigated the possible role of three ETS genes in controlling two important p53 inducible genes, GADD45 and GADD153. Our findings show an optimal EBS in the GADD153 promoter, and that these sequences specifically bind ETS1 and FLI1 protein, but not ETS2. The binding of FLI-1 was completely blocked and the binding of ETS1 strongly inhibited by the insertion of one single point mutation in the GADD153 EBS (Figures 2 and 3).

Both ETS1 and FLI-1 proteins strongly activate GADD153 promoter activity, increasing gene transcription by fourfold and fivefold respectively in reporter gene assays (Figure 5). ETS2 protein expression results only in a weak induction of the CAT reporter gene. Interestingly, when the promoter region immediately upstream of the EBS was deleted, we could observe an inverse correlation in the transcriptional activity of ETS1 and FLI-1 proteins (Figure 5). In fact, we observe about a $30 \%$ loss of activity for ETS1, and a $300 \%$ increase for FLI-1 protein (Figures 4 and 5). Finally, when the EBS was deleted from the constructs, as in the GADD153EBS-CAT reporter plasmid p9028, transcriptional activation by all of the ETS expression vectors disappeared further confirming the specificity of the EBS structure in the GADD153 promoter, and its high affinity for the ETS proteins. Our

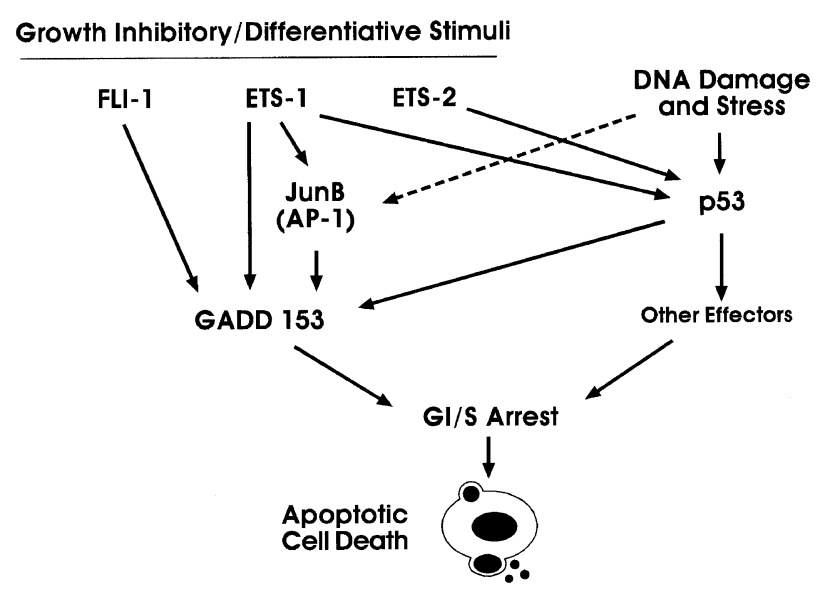

Figure 6 Multiple pathways of GADD153 activation leading to apoptosis

results show that the DNA region upstream of the EBS is critical for the fine tuning of normal GADD153 expression by the ETS1 and FLI-1 proteins because it has a selective suppressive or promoting effect on the transcriptional activity. These results are of immense importance because they establish a novel mechanism of activation of GADD153 by ETS1 and FLI-1 transcription factors, demonstrating how specific and crucial the structure of the ETS binding region is for the regulation of GADD153 expression by ETS1 and FLI-1.

Based on our findings and on existing literature, we propose a two level model of GADD153 activation by ETS genes, directly transactivating its promoter, or indirectly by inducing p53 expression although other mechanisms of transactivation are possible (Figure 6). Data presented herein implicate ETS1 and FLI-1 as participants in novel 
mechanisms of activation of GADD153. These data suggest that the sequence of the GADD153 ETS binding motif is critical for each one of the ETS transcription factors and their DNA binding ability, indicating that different ETS family members bind and regulate GADD153 transcription with distinct mechanisms.

We have previously shown that ETS1 and ETS2, but not FLI-1 upregulate p53 expression, implying indirect effects upon p53 effector genes. ${ }^{23}$ Here we have found that FLI-1 and ETS1 both bind and upregulate the GADD153 promoter, and that ETS2 does not directly upregulate GADD153 expression. Thus ETS1 participates in multiple pathways intersecting at the GADD153 promoter, for example, via p53, junB, and directly on the EBS (Figure 6 ). ETS2 could only affect GADD153 regulation indirectly via p53. FL1-1 regulation of GADD153 would be independent of p53 since we have shown that it has no affinity for the p53 promoter EBS. ${ }^{23}$ ETS genes expression has been linked consistently to proliferative/differentiative processes, $^{30,41,42,49}$ but have never been related to DNA damage or to any other kind of cellular stress, except recently to oxidative stress. ${ }^{39}$ Thus, it is likely that this ETS regulatory mechanism of GADD153 transcription represents novel pathways to control cell growth and differentiation by GADD153 activation, in response to differentiative stimuli like oxidative stress.

\section{Materials and Methods}

\section{BLASTN analysis of the GADD153 promoter}

The GADD153 promoter sequence (GB: ) was searched for EBSs (C/A $G$ G A A A/G C/T A/G) using the online BLASTN program hosted by the $\mathrm{NCBI}$ webpage.

\section{Sequence of GADD153 EBS oligonucleotides used in electrophoretic mobility shift assay}

Wild type and mutant oligonucleotides corresponding to the putative Ets binding sequences of GADD153 EBS, E74 and the ETS1-3 genes were chemically synthesized on an ABI DNA synthesizer (California, USA) and purified through OPC column (Figure 2). For electrophoretic mobility gel shift assays, the oligonucleotides were annealed, as described, and labeled with [ ${ }^{32}$ P]dCTP using the Klenow enzyme.

\section{Protein-DNA-binding assay}

Protein-DNA interactions were investigated by Electrophoretic mobility shift assay (EMSA), ${ }^{50}$ using $32 \mathrm{P}$-end-labeled synthetic GADD153 EBS annealed oligonucleotides and either the ETS1, ETS2 and FLI-1 nuclear extracts produced by the baculoviral system in SF-9 insect cells, or ETS2 recombinant protein produced in $E$. Coli. as described. ${ }^{34}$ DNA binding was performed in a binding buffer containing 50,000 c.p.m. of a ${ }^{32} \mathrm{P}$-labeled probe for $20 \mathrm{~min}$. at $4{ }^{\circ} \mathrm{C}$, in the presence or absence of excess, unlabeled cognate or mutated oligonucleotide, and the protein-DNA complexes were analyzed on a $4 \%$ polyacrylamide gel containing $0.25 \times \mathrm{TBE}(1 \times \mathrm{TBE}$ is $50 \mathrm{mM}$ Tris base $-50 \mathrm{mM}$ boric acid $-1 \mathrm{mM}$ ethylenediaminetetraacetic acid [EDTA]). The gel was dried and autoradiographed. Mouse antihuman ETS1 monoclonal antibody E44, was kindly given by Dr. Robert Fisher (National Cancer Institute, Frederick, MD, USA).

\section{Construction of CAT reporter and ETS expression plasmids}

CAT reporter plasmids were constructed by ligating the GADD153 EBS sequences at the Hindlll site of pBLCAT2, which is located upstream of the TK promoter TATA box, and were kindly provided by Dr. Nikky J Holbrook (National Institute on Aging, Baltimore, MD, USA). The ETS expression plasmids pSGE1(ETS1), pSGE2 (ETS2), and pSGT20 (ERGB/Hu-FLI-1) were obtained by cloning DNA fragments of ETS1, ETS2 and ERGB/Hu-FLI-1 genes, respectively, at the BamHI site of vector pSG5 (Stratagene, California, USA). This vector contains the SV40 promoter upstream of cloning sites. ${ }^{34}$

\section{Cell culture transfection and CAT assay}

COS cells were grown in DMEM supplemented with $10 \%$ calf serum in a $5 \% \mathrm{CO}_{2}$ atmosphere. The culture media and serum were obtained from Gibco and Applied Biologicals (MA, USA). The cotransfection experiments, performed by the calcium phosphate technique, were done using CAT reporter plasmids and ETS expression vectors at a ratio of either $1: 5$ or $1: 10, \mathrm{pCH} 110$ (bgalactosidase vector) was used as an internal standard for transfection efficiency. ${ }^{34}$ The cells were harvested after $48-72 \mathrm{~h}$ and the cell extracts were normalized for the protein concentrations. Cell extracts were then incubated with $\left[{ }^{14} \mathrm{C}\right]$ chloramphenicol and acetyl CoA for $12 \mathrm{~h}$ and assayed for CAT activity by thin layer chromatography and quantitation on the Ambis radioisotopic imaging system, as previously described. ${ }^{34}$ The level of CAT stimulation was determined by comparison of co-transfection with control plasmids after normalization to $\beta$-galactosidase activity. All transfection experiments and the CAT assays were repeated multiple times.

\section{Acknowledgements}

We thank Lois Robinson and Vincent Li for technical assistance. This work was supported by an MRC Group Grant to A Seth.

\section{References}

1. Diller L, Kassel J, Nelson CE, Gryka MA, Litwak G, Gebhardt M, Bressac B, Ozturk M, Baker SJ, Vogelstein B et al. (1990) p53 functions as a cell cycle control protein in osteosarcomas. Mol. Cell. Biol. 10: $5772-5781$

2. Martinez JD, Craven MT, Joseloff E, Milczarek G and Bowden GT (1997) Regulation of DNA binding and transactivation in $p 53$ by nuclear localization and phosphorylation. Oncogene 14: 2511-2520

3. Vogelstein B and Kinzler KW (1992) p53function and dysfunction. Cell 70:523526

4. Dulic V, Kaufmann WK, Wilson SJ, TIsty TD, Lees E, Harper JW, Elledge SJ and Reed SI (1994) p53-dependent inhibition of cyclin-dependent kinase activities in human fibroblasts during radiation-induced G1 arrest. Cell 76: 1013-1023

5. el-Deiry WS, Tokino T, Velculescu VE, Levy DB, Parsons R, Trent JM, Lin D, Mercer WE, Kinzler KW and Vogelstein B (1993) WAF1, a potential mediator of p53 tumor suppression. Cell 75: 817-825

6. Kastan MB, Zhan Q, el-Deiry WS, Carrier F, Jacks T, Walsh WV, Plunkett BS, Vogelstein B and Fornace Jr AJ (1992) A mammalian cell cycle checkpoint pathway utilizing p53 and GADD45 is defective in ataxia-telangiectasia. Cell 71: 587-597

7. Smith ML, Chen IT, Zhan Q, Bae I, Chen CY, Gilmer TM, Kastan MB, O'Connor PM and Fornace Jr AJ (1994) Interaction of the p53-regulated protein Gadd45 with proliferating cell nuclear antigen [see comments]. Science 266: 1376-1380

8. el-Deiry WS, Kern SE, Pietenpol JA, Kinzler KW and Vogelstein B (1992) Definition of a consensus binding site for p53. Nat. Genet. 1: 45-49 
9. Fornace Jr AJ, NebertDW, Hollander MC, Luethy JD, Papathanasiou M, Fargnol $J$ and Holbrook NJ (1989) Mammalian genes coordinately regulated by growth arrest signals and DNA- damaging agents. Mol. Cell. Biol. 9: 4196-4203

10. Chen Q, YuK, HolbrookNJ and Stevens JL. (1992) Activation of the growth arrest and DNA damage-inducible gene gadd 153 by nephrotoxic cysteine conjugates and dithiothreitol. J. Biol. Chem. 267: 8207-8212

11. Gately DP, Jones JA, Christen R, Barton RM, Los G and Howell SB (1994) Induction of the growth arrest and DNA damage-inducible gene GADD153 by cisplatin in vitro and in vivo. Br. J. Cancer. 70: 1102-1106

12. Gujuluva CN, Baek JH, Shin KH, Cherrick HM and Park NH (1994) Effect of UVirradiation on cell cycle, viability and the expression of $p 53$, gadd 153 and gadd 45 genes in normal and HPV-immortalized human oral keratinocytes. Oncogene 9: $1819-1827$

13. Kashima N, Ueohzono T, Fornace Jr AJ and Ide T (1995) Induction of gadd153 gene in G0-specific ts mutantcells at nonpermissive temperature. Exp. Cell. Res. 217: $324-328$

14. Luethy JD and Holbrook NJ (1992) Activation of the gadd153 promoter by genotoxic agents: a rapid and specific response to DNA damage. Cancer Res. 52: $5-10$

15. Papathanasiou MA, Kerr NC, Robbins JH, McBride OW, Alamo Jr I, Barrett SF, Hickson ID and Fornace Jr AJ (1991) Induction by ionizing radiation of the gadd45 gene in cultured human cells: lack of mediation by protein kinase $\mathrm{C}$. Mol. Cell. Biol. 11: 1009-1016

16. Price BD and Calderwood SK (1992) Gadd45 and Gadd153 messenger RNA levels are increased during hypoxia and after exposure of cells to agents which elevate the levels of the glucose-regulated proteins. Cancer Res. 52: 38143817

17. Ron D and Habener JF (1992) CHOP, a novel developmentally regulated nuclear protein that dimerizes with transcription factors C/EBP and LAP and functions as a dominant- negative inhibitor of gene transcription. Genes Dev. 6: $439-453$

18. Luethy JD and Holbrook NJ (1994) The pathway regulating GADD153 induction in response to DNA damage is independent of protein kinase $C$ and tyrosine kinases. Cancer Res. 54: 1902s-1906s

19. Zhan Q, Bae I, Kastan MB and Fornace Jr AJ (1994) The p53-dependent gammaray response of GADD45. Cancer Res. 54: 2755-2760

20. Zhan Q, Lord KA, Alamo Jr I, Hollander MC, Carrier F, Ron D, Kohn KW, Hoffman B, Liebermann DA and Fornace Jr AJ (1994) The gadd and MyD genes define a novel set of mammalian genes encoding acidic proteins that synergistically suppress cell growth. Mol. Cell. Biol. 14: 2361-2371

21. Gately DP, Sharma A, Christen RD and Howell SB (1996) Cisplatin and taxo activate different signal pathways regulating cellular injury-induced expression of GADD153. Br. J. Cancer 73: 18-23

22. Guyton KZ, Xu Q and Holbrook NJ (1996) Induction of the mammalian stress response gene GADD 153 by oxidative stress: role of AP- 1 element. Biochem. J. 314: $547-554$

23. Venanzoni MC, Robinson LR, Hodge DR, Kola I and Seth A (1996) ETS1 and ETS2 in p53 regulation: spatial separation of ETS binding sites (EBS) modulate protein: DNA interaction. Oncogene 12: 1199-1204

24. Huang CC, Papas TS and Bhat NK (1997) A variant form of ETS1 induces apoptosis in human colon cancer cells. Oncogene 15: 851-856

25. Muthusamy N, Barton K and Leiden JM (1995) Defective activation and survival of T cells lacking the Ets-1 transcription factor. Nature 377: 639-642

26. YiH, Fujimura Y, Ouchida M, Prasad DD, Rao VN and Reddy ES (1997) Inhibition of apoptosis by normal and aberrant Fli-1 and erg proteins involved in human solid tumors and leukemias. Oncogene 14: 1259-1268

27. Coffer P, de Jonge M, Mettouchi A, Binetruy B, Ghysdael J and Kruijer W (1994) junB promoter regulation: Ras mediated transactivation by $\mathrm{c}-\mathrm{Ets}-1$ and $\mathrm{c}-\mathrm{Ets}-2$. Oncogene 9: 911-921

28. Funaoka K, Shindoh M, Yoshida K, Hanzawa M, Hida K, Nishikata S, Totsuka Y and Fujinaga K (1997) Activation of the p21(Waf1/Cip1) promoter by the ets oncogene family transcription factor E1AF. Biochem. Biophys. Res. Commun. 236: $79-82$

29. Seth A, Ascione R, Fisher RJ, Mavrothalassitis GJ, Bhat NK and Papas TS (1992) The ets gene family. Cell Growth Differ. 3: 327-334

30. Kola I, Brookes S, Green AR, Garber R, Tymms M, Papas TS and Seth A (1993) The Ets1 transcription factor is widely expressed during murine embryo development and is associated with mesodermal cells involved in morphogenetic processes such as organ formation. Proc. Natl. Acad. Sci. USA 90: 75887592
31. Maroulakou IG, Papas TS and Green JE (1994) Differential expression of ets-1 and ets-2 proto-oncogenes during murine embryogenesis. Oncogene 9: 1551 1565

32. Schmid P, Lorenz A, Hameister H and Montenarh M (1991) Expression of p53 during mouse embryogenesis. Development 113: 857-865

33. Ascione R, Thompson D, Thomas R, Panayiotakis A, Ramsay R, Tymms M, Kola I and Seth A (1992) Influence of nucleotides flanking the -GGAA- core sequence on ETS1 and ETS2 DNA-binding activity and the mechanism of ETS1 autoregulation. International Journal of Oncology 1: 631-637

34. Seth A, Robinson L, Thompson DM, Watson DK and Papas TS (1993) Transactivation of GATA-1 promoter with ETS1, ETS2 and ERGB/Hu-FLI-1 proteins: stabilization of the ETS1 protein binding on GATA-1 promoter sequences by monoclonal antibody. Oncogene 8: 1783-1790

35. Jackman J, Alamo Jr I and Fornace Jr AJ (1994) Genotoxic stress confers preferential and coordinate messenger RNA stability on the five gadd genes. Cancer Res. 54: $5656-5662$

36. Lord KA, Abdollahi A, Hoffman-Liebermann B and Liebermann DA (1990) Dissection of the immediate early response of myeloid leukemia cells to terminal differentiation and growth inhibitory stimuli. Cell Growth Differ. 1: 637-645

37. Wang XZand Ron D (1996) Stress-induced phosphorylation and activation of the transcription factor CHOP (GADD153) by p38 MAP Kinase. Science 272: 13471349

38. Carlson SG, Fawcett TW, Bartlett JD, Bernier M and Holbrook NJ (1993) Regulation of the C/EBP-related gene gadd153 by glucose deprivation. Mol. Cell. Biol. 13: $4736-4744$

39. Yasuda M, Ohzeki Y, Shimizu S, Naito S, Ohtsuru A, Yamamoto T and Kuroiwa Y (1999) Stimulation of in vitro angiogenesis by hydrogen peroxide and the relation with ETS-1 in endothelial cells. Life Sci. 64: 249-258

40. Ascione R, Watson D and Papas T (1993) Family of ETS genes as transcriptional regulatory factors. In: Adolph KW (ed.), Genome Research in Molecular Medicine and Virology, pp. 199-218, Academic Press, New York

41. Bhat NK, Komschlies KL, Fujiwara S, Fisher RJ, Mathieson BJ, Gregorio TA, Young HA, Kasik JW, Ozato K and Papas TS (1989) Expression of ets genes in mouse thymocyte subsets and T cells. J. Immunol. 142: 672-678

42. Boulukos KE, Pognonec P, Sariban E, Bailly M, Lagrou C and Ghysdael J. (1990) Rapid and transient expression of Ets2 in mature macrophages following stimulation with CMGF, LPS, and PKC activators. Genes Dev. 4: 401-409

43. Papas TS, Blair DG, Watson DK, Yuan CC, Ruscetti SK, Fujiwara S, Seth AK, FisherRJ, Bhat NK, Mavrothalassitis Gand etal. (1990) The ETS family of genes: structural analysis, gene products, and involvement in neoplasia and other pathologies. Prog. Clin. Biol. Res. 360: 137-168

44. Pardanaud L and Dieterlen-Lievre F (1993) Expression of C-ETS1 in early chick embryo mesoderm: relationship to the hemangioblastic lineage. Cell Adhes. Commun. 1: 151-160

45. Seth A and Papas TS (1990) The c-ets-1 proto-oncogene has oncogenic activity and is positively autoregulated. Oncogene 5: 1761-1767

46. Seth A, Watson DK, Blair DG and Papas TS (1989) C-ets-2 protooncogene has mitogenic and oncogenic activity. Proc. Natl. Acad. Sci. USA 86: 7833-7837

47. Sumarsono SH, Wilson TJ, Tymms MJ, Venter DJ, Corrick CM, Kola R, Lahoud MH, Papas TS, Seth A and Kola I (1996) Down's syndrome-like skeletal abnormalities in Ets2 transgenic mice. Nature 379: 534-537

48. Suzuki H, Romano-Spica V, Papas TS and Bhat NK (1995) ETS1 suppresses tumorigenicity of human colon cancer cells. Proc. Natl. Acad. Sci. USA 92: $4442-4446$

49. Bhat NK, Fisher RJ, Fujiwara S, Ascione R and Papas TS (1987) Temporal and tissue-specific expression of mouse ets genes. Proc. Natl. Acad. Sci. USA 84: $3161-3165$

50. Seth A, Robinson L, Panayiotakis A, Thompson DM, Hodge DR, Zhang XK, Watson DK, Ozato K and Papas TS (1994)The endo A enhancer contains multiple Ets binding site repeats and is regulated by Ets proteins. Oncogene 9: $469-477$ 